\title{
Reverse Osmosis powered by Concentrating Solar Power (CSP): A case study for Trapani, Sicily
}

\author{
Mahran K.A. Ahmed ${ }^{\mathrm{a}, *}$, João P. Cardoso ${ }^{\mathrm{b}}$, J. Farinha Mendes ${ }^{\mathrm{b}}$, Sérgio Casimiro ${ }^{\mathrm{b}, \mathrm{c}, 11}$ \\ ${ }^{a}$ Loughborough University, Leicestershire, United Kingdom \\ ${ }^{\mathrm{b}}$ Laboratório Nacional de Energia e Geologia, I.P., Lisboa, Portugal \\ ${ }^{\mathrm{c}}$ Sustainable Energy Systems, MIT-Portugal Program, Lisboa, Portugal \\ * Corresponding author, email address: mahran.abdelkarim@,gmail.com
}

\begin{abstract}
The objective of this paper is to analyse the physical performance of two technologies in a water and electricity co-generation scheme: Concentrated Solar Power (CSP) plant coupled to a Reverse Osmosis (RO) unit for a location in the city of Trapani, in southern Italy. The modelled system is compared with the results of another study [2], in which a Multi-Effect Desalination (MED) is powered by a CSP plant for the same location in Italy, using as reference an existing stand-alone gas powered MED plant located at Trapani [3] (which has operated until very recently). The overall aim is to assess and compare these two cogeneration schemes, using as reference the existing MED plant. This work was conducted using as the main simulation tool: the System Advisor Model (SAM) developed by the US National Renewable Energy Laboratory (NREL); a recent upgrade to SAM made available to this work through Laboratório Nacional de Energia e Geologia I.P. (LNEG); and the Reverse Osmosis System Analysis (ROSA) developed by the Dow Chemical Company. A technical visit to a real commercial RO plant in the south of Portugal (Alvor) was conducted, and the data gathered was used in the validation of the ROSA model. The results for the Trapani case study show that the CSP-RO arrangement has the capability to produce $\sim 50 \%$ of the total production of the full scale plant at Trapani, if operated at nominal capacity, year round. Also, the CSP-RO system provides $\sim 20 \%$ more electricity and water than the CSP-MED system throughout the studied period of one year. The two co-generation schemes provide promising potential to fight the issues related to fresh water shortages and dependency on fossil fuelled desalination. Thus, they can aid in decreasing the effects associated with $\mathrm{CO}_{2}$ emissions and climate change.
\end{abstract}

Keywords: Reverse Osmosis; Concentrated Solar Power; System Analysis; Multi-Effect Desalination; Solar Powered Desalination; System Advisor Model; Renewable Desalination.

\section{INTRODUCTION}

The use of seawater desalination to provide fresh drinking water is a well-established and flourishing industry. The two main technologies used are thermal desalination and Reverse Osmosis (RO) membrane filtration. In the main market for the desalination industry - the Middle East - large scale desalination plants are heavily used for the production of fresh water. It is expected that at current growth rates and global climate changes, water demand in the Middle East and North Africa (MENA) region alone is going to increase by around $50 \%$ in the next 35 years [1]. The utilization of renewable energy sources for the production of drinking water is of great global interest, as it can potentially provide a sustainable solution for fresh water production in regions like the Middle East. The work described in this paper falls under this framework. It focuses on studying the potential of seawater desalination systems powered by Concentrated Solar Power (CSP) plants as a means of renewable desalination. RO and MED were selected to be analysed in this work as they present the best performances within the mature technologies operating in the desalination market.

\subsection{Methodology}

The steps applied to perform this study are based on freely available computer modelling tools used for the simulation of RO and CSP operation. These steps include, firstly the validation of the Reverse Osmosis System Analysis (ROSA) tool with operational data for nominal conditions from a small scale water desalination plant in Alvor, Portugal. Secondly, the utilisation of the System Advisor Model (SAM) developed by the National Renewable Energy Laboratory (NREL) to simulate a CSP plant, together with ROSA to simulate the RO unit using data for the location of Trapani. The results of both models were combined to obtain the performance of a CSP-RO co-generation scheme. Thirdly, an analysis and comparison between: 1) the CSP-RO modelled; 2) a CSP-MED co-generation scheme previously studied in [2]; and 3) data from a real TVC-MED plant that exists in Trapani, Sicily [3].

\footnotetext{
${ }^{1}$ Present address: Center for Complex Engineering Systems, King Abdulaziz City for Science and Technology, Riyadh, Saudi Arabia.
} 


\section{REVERSE OSMOSIS SYSTEM ANALYSIS (ROSA) TOOL}

ROSA can be used to estimate the performance of a new RO system under design conditions, or the performance of an existing RO system under off-design conditions. This projected performance is based on the nominal performance specification for the DOW FILMTECTM element(s) (or membranes) used in that system. Accurate results can be obtained very quickly using the ROSA computer program. Thus, it can be used to modify and optimize the design of an RO system. The entire system calculation methods will not be described in detail, however the major governing equations and parameters will be briefly described in this section. These equations were also used previous work [4] to develop a computer model, similar to ROSA, to predict the performance of RO systems based on membrane-tomembrane analysis (single element performance).

\subsection{Design Equations and Parameters}

The performance of a specified RO system, in ROSA, is defined by its feed pressure (or permeate flow, if the feed pressure is specified) and its salt passage (amount of salt passing through the membrane). In its simplest form, the permeate flow (Q) through an RO membrane is a function of the membrane active area (wet area) (S), the Net Driving Pressure (NDP) $(\Delta \mathrm{P}-\Delta \pi)$ and the membrane permeability. The permeate water flux can be calculated from the following equation [5]:

$Q=(A)(S)(\Delta P-\Delta \pi)$

Van't Hoff's theoretical osmotic pressure equation is adapted to operational conditions by DOW FILMTEC ${ }^{\mathrm{TM}}$, and then used to calculate the osmotic pressure of the feed solution:

$\pi_{f}=1.12(273+T) \Sigma m_{j}$

For a given recovery rate, applied feed pressure $\left(\mathrm{P}_{\mathrm{f}}\right)$ increases with the increasing feed osmotic pressure. It should be noted that there's a minor drop in feed pressure as the feed solution passes from one membrane to another in the pressure vessel due to friction. Pressure drop in the concentrate side of an RO membrane can be estimated from the following equation:

$P_{c d}=0.01 n q_{f c}^{1.7}$

The average concentrate side flow rate $\left(\mathrm{q}_{\mathrm{fc}}\right)$, is equal to the arithmetic average of the feed and concentrate flow rates as in the following equation:

$q_{f c}=\frac{Q_{f+} Q_{c}}{2}$

In a typical RO process, as water flows thorough the membrane and the membrane rejects salts, a boundary layer is formed near the membrane surface in which salt concentration exceeds the salt concentration in the bulk solution by a factor equal to the concentration polarization value [5]. This parameter can be calculated from the following equation:

$C P=\frac{C_{w}}{C_{b}}$

Experimentally, DOW FILMTEC ${ }^{\mathrm{TM}}$ has determined that $\mathrm{CP}=\mathrm{EXP}(0.7 \mathrm{R})$. Where $\mathrm{R}$ is the recovery rate. Equation (5) shows that the nominal salt rejection rate in $\mathrm{RO}$ membranes is lower than the true rejection rate. The actual rejection rate can be defined as the ratio between the permeate concentration to the feed concentration at the membrane surface:

$R_{j}=1-\left(C_{p} / C_{f}\right)$

Although the membranes are designed for high rejection, some amounts of salt always pass through the membranes. In the ROSA design equations, the salt passage is by salt diffusion through the membrane. Thus, the salt flux is proportional to the salt concentration difference between both sides of the membrane. The proportionality constant is known as the salt diffusion coefficient or the B factor.

$N A=B\left(C_{f}-C_{p}\right)$

The quality of the permeate is proportional to the B factor, concentration polarization, salt rejection, feed concentration and membrane active area. It can be calculate using the following equation: 
$C_{p}=B * C_{f c} * C P * R_{j} * \frac{S}{Q_{p}}$

The permeate concentration $C_{p}$ represents the quality of the treated water which is a function of membrane type and operational conditions such as feed water temperatures and TDS levels. The permeate osmotic pressure can be calculated using the feed osmotic pressure as a reference:

$\pi_{p}=\pi_{f}\left(1-R_{j}\right)$

Permeate flow through the RO membrane can be expressed more completely by rearranging Eq. 1 taking into account the effect of the permeate osmotic pressure, average pressure drop in the RO vessel, permeate pressure, and fouling factor: Eq. 1 can be rewritten as follows:

$Q_{p}=(A)(S)(T C F)(F F)\left(P_{f}-\frac{P_{c d}}{2}-P_{p}-\pi_{\text {ave }}+\pi_{p}\right)$

The fouling factor is applied to membrane to simulation aging and lose of permeability due to compaction and scale fouling. Typically a fouling factor of 1 is applied to new membrane, and a fouling factor between 0.65 to 0.85 for three year old membranes and onwards. Also, because the performance of the RO membranes is typically tested at $25{ }^{\circ} \mathrm{C}$, a Temperature Correction Factor (TCF) is considered were suitable in the equations above to adjust the temperature differences. TCF is determined using the following equations:

$T C F=E X P\left[2640\left(\frac{1}{298}-\frac{1}{273+T}\right)\right] ; \mathrm{T} \geq 25^{\circ} \mathrm{C}$
$T C F=E X P\left[3020\left(\frac{1}{298}-\frac{1}{273+T}\right)\right] ; \mathrm{T} \leq 25^{\circ} \mathrm{C}$

\section{ROSA VALIDATION}

The reverse osmosis plant data used in the validation procedure was provided by the plant operators of a desalination plant in the southern city of Alvor, Algarve, Portugal on October $10^{\text {th }} 2014$. The plant has a water production of around $800 \mathrm{~m}^{3} /$ day, and the data referred to nominal operation of the plant

\subsection{Plant Configurations}

The plant is composed of a pre-treatment system, 54 semipermeable membranes ( 9 pressure vessels with 6 membranes each) as seen in figure 1, an energy recovery system (figure 2), and three main pumps: a low pressure pump (1 bar) between the intake and pre-treatment filters, a high pressure pump (60 bars) forcing the water through the membranes, and the energy recovering pump (56 bars). It also has a post-treatment system and a reservoir for produced water of $1000 \mathrm{~m}^{3}$. A high efficiency energy recovery system is used, it recovers energy by transferring most of the remaining pressure contained in concentrate stream to a portion of the total feed water mass flow. This system allows the mixing of a small amount of brine water (5-10\%) with the supply water, which can compensate for minimum required salinity to run the membranes to produce the targeted permeate quality.

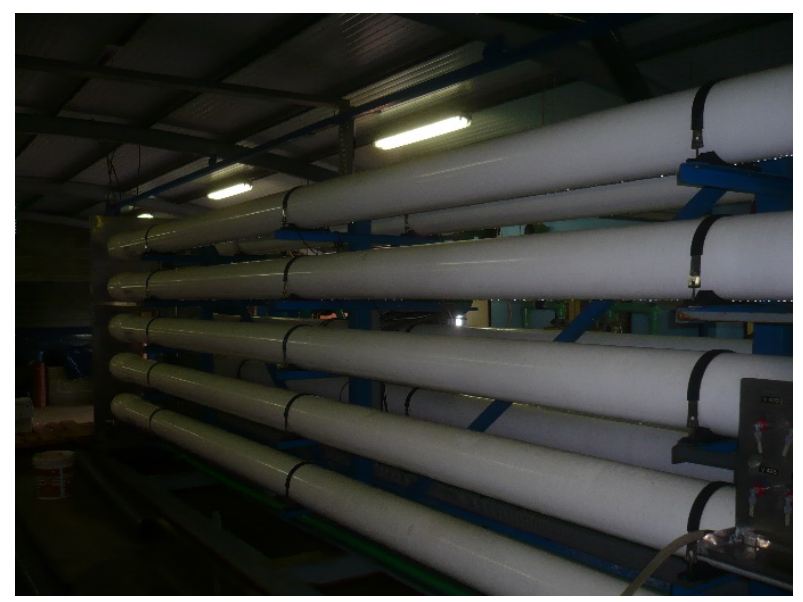

Figure 1: Alvor plant membrane assembly 
As part of this study, the Reverse Osmosis System Analysis (ROSA) model, a product of DOW FILMTEC ${ }^{\mathrm{TM}}$, is validated against another manufacturer's desalination membranes (Toray). Such experiments are found in the literature [6]. The Alvor plant uses Toray TM820C-400 membranes. These are high rejection seawater membranes, with an area of $37 \mathrm{~m}^{2}$ per element that according to the manufacturer maximize productivity and enable predictive system design. The current membranes being used at Alvor were replaced in a successive manner, one by one, starting from the first maintenance operation carried out, and by May 2014, they had all been replaced. (the first element of each pressure vessel is normally replaced during each major maintenance operation, being the new replacement placed at the back of each pressure vessel).

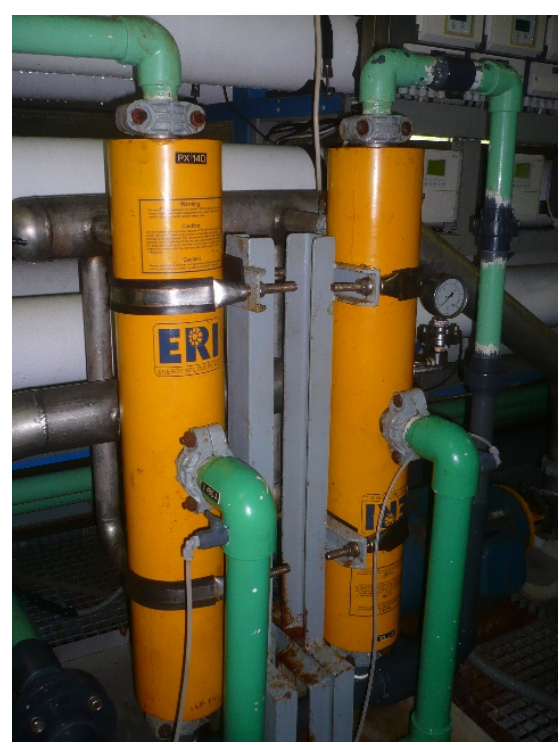

Figure 2: Energy Recovery Device

In the validation procedure carried out in this work, it is assumed that all membranes are new. The RO cross reference tool [7] is used to determine the corresponding Dow membrane type with similar physical and operating characteristics to the ones used at the Alvor plant.

The plant is located at $17 \mathrm{~m}$ above sea level. It has three wells. One used as a water intake at $-8 \mathrm{~m}$ below the sea level, one used to monitor the water level, salinity and temperature. In addition to a third well which acts as a brine discharge located at $30 \mathrm{~m}$ depth and connected to underground currents that carry the brine into the sea. It is the furthest away from the plant to ensure that no mixing occurs between the feedwater and the brine. The wells are located near the coast and the changing tide levels can have an impact on the operation of the plant by causing a mixture of underground fresh water streams with the seawater underground intake, which can lead to a decrease in the salinity of the feed water throughout the year (depending on the rainfall precipitation levels).

\subsection{Validation Input Data}

The validation of the ROSA model is done using the quality, mass flow rate, and temperature of the total feed water. The main parameters used in the validation are shown in table 1.

\subsection{Outputs Results}

The main results of the validation process are shown in table 2, where real operational data at nominal conditions from the RO plant in Alvor is compared to the model outputs for the general operating parameters of permeate and concentrate flow rates and salinities, as well the feed pump pressure.

The model predictions fall in the line with the operational data from the plant, with an error margin of $\sim 10 \%$ compared to the real plant outputs (figure 3). The most important finding is that the model under predicted the feed pump pressure by around $7.5 \%$. These marginal differences can be attributed to simplifying assumptions within the models mathematical algorithms, and to the quality of the real data gathered. Performance parameters for nominal operation, regarding the water quality, were not collected during the technical visit to the plant, as it was not in operation during the site visit and a shutdown procedure in which fresh water is flushed through the membranes had been performed. 
Table 1: ROSA Validation Inputs

\begin{tabular}{l|ll}
\hline Parameter & Value & Units \\
\hline $\begin{array}{l}\text { Pre-stage } \Delta \mathbf{P} \\
\text { Feed Water salinity (TDS) }\end{array}$ & 0.345 & $\mathrm{Bar}$ \\
No. of passes & 13800 & $\mathrm{mg} / \mathrm{l}$ \\
No. of stages & 1 & - \\
Flow factor & 1 & - \\
$\begin{array}{l}\text { Recovery rate } \\
\text { Feed Flow rate }\end{array}$ & 40 & - \\
Membrane type & 87 & $\%$ \\
& $\mathrm{SW} 30 \mathrm{XHR}-$ & - \\
No. of membranes in & $-\mathrm{h}$ \\
pressure vessel & $600 \mathrm{i}$ & \\
No. of pressure vessels & & - \\
pH & 9 & \\
Water Temperature & 5.7 & - \\
Pump efficiency & 18 & - \\
\hline
\end{tabular}

Table 2: ROSA Validation Outputs

\begin{tabular}{|l|l|l|l|}
\hline Parameter & Real data & $\begin{array}{l}\text { Modelled } \\
\text { data }\end{array}$ & $\begin{array}{l}\text { Difference } \\
(\%)\end{array}$ \\
\hline $\begin{array}{l}\text { Permeate } \\
\text { flow rate }\end{array}$ & $34.0 \mathrm{~m}^{3} / \mathrm{h}$ & $34.8 \mathrm{~m}^{3} / \mathrm{h}$ & $+2.4 \%$ \\
\hline $\begin{array}{l}\text { Concentrate } \\
\text { flow rate }\end{array}$ & $54.0 \mathrm{~m}^{3} / \mathrm{h}$ & $52.5 \mathrm{~m}^{3} / \mathrm{h}$ & $-2.7 \%$ \\
\hline $\begin{array}{l}\text { Permeate } \\
\text { salinity }\end{array}$ & $165 \mathrm{mg} / \mathrm{l}$ & $149.6 \mathrm{mg} / 1$ & $-9.3 \%$ \\
\hline $\begin{array}{l}\text { Concentrate } \\
\text { salinity }\end{array}$ & $\begin{array}{l}52988 \\
\mathrm{mg} / 1\end{array}$ & $\begin{array}{l}55431 \\
\mathrm{mg} / 1\end{array}$ & $+4.6 \%$ \\
\hline $\begin{array}{l}\text { Feed pump } \\
\text { pressure }\end{array}$ & $60.0 \mathrm{bar}$ & $55.5 \mathrm{bar}$ & $-7.5 \%$ \\
\hline
\end{tabular}

As some of the water used for flushing was mixed with each of the permeate and concentrate in the tanks, a direct measurements of conductivity would not return representative results of normal plant operation. The conductivity data provided by the plant operators was used to estimate the feed water total dissolved solids based on a derived conductivity-to-total dissolved solids conversion factor [6]. Although it eliminates time consuming analytical testing of the water, it is not the most accurate method for determining feed water TDS values.

Additionally, it is possible that ROSA incorporates a "safety factor" when predicting the required feed pressure, as it is used to size the feed pump(s). Such an embedded factor might influence the accuracy of the model, but gives a conservative approach from a design perspective. A conservative prediction might increase the reliability of water production, but at the expense of less efficient operation. Overall, the authors conclude that the ROSA model provides an approximate estimate of system performance that can be used in early stages of RO system design.

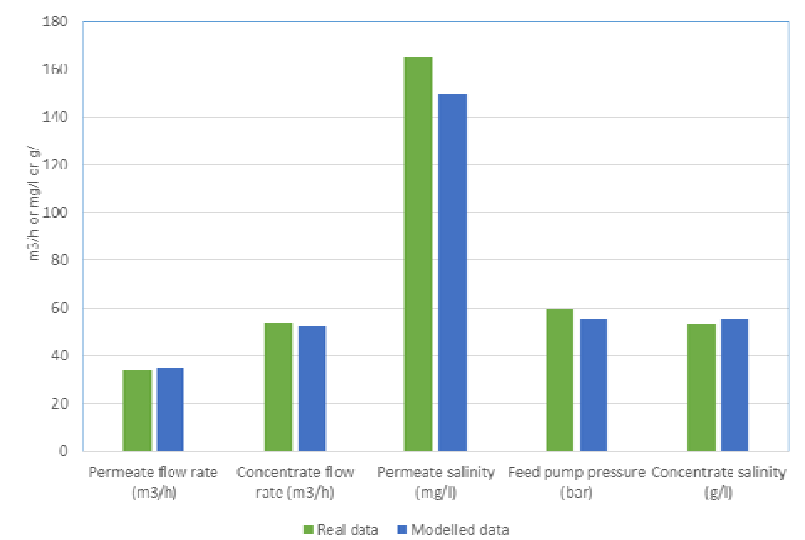

Figure 3 - RO Real Data versus Modelled Data 


\section{CASE STUDY}

\subsection{System Description}

The aim of this study is to simulate the performance of a parabolic trough plant coupled with a seawater desalination RO unit and compare it with an existing large-scale (Thermal Vapor Compression) TVC-MED parallel feed desalination plant, capable of producing $36000 \mathrm{~m}^{3} / \mathrm{d}$ [8]. This MED plant was chosen as reference for this case study, firstly, because it is one of the few plants with detailed design information available in the literature. Secondly, because it was possible to use data from a previous study regarding the operation of this MED plant using natural gas versus the option of using a CSP plant as power source [2]. Thirdly, no relevant detailed comparison is available in the literature regarding the operation of CSP-RO, versus CSP-MED, versus the operation of an existing plant for the same site.

Such a coupling (CSP-RO) will initially assume that all the net electrical power output from the power block will drive the RO unit's high-pressure pump and both pre and post-treatment systems. The unit's main operating parameters, that is, the recovery and feed pressure, are established by considering membrane control and operation limits. The CSP-RO system modelled consists of an $110 \mathrm{MW}_{\mathrm{e}}$ parabolic trough CSP plant with a conventional steam Rankine cycle coupled with a large-scale two-stage RO plant (first stage assumed to have 49 pressure vessels, and second stage 36 pressure vessels, each pressure vessel with 6 elements). The size selected for the CSP plant is much larger than necessary $(\sim 110$ MWe instead of $\sim 6.7 \mathrm{MWe}$ gross) in order to compare the performance of the modelled CSP-RO system to that of a low temperature CSP-MED, with an equal power capacity previously studied in [2] for the same geographical location. The RO system is divided into six parallel connected trains, to enable flexible partial operation (each train with 2 stages). The RO system has a total recovery of $45 \%$, and energy is recovered using a high efficiency pressure exchanger. The first stage recovers $37.6 \%$, and the second stage $11.8 \%$ (the second stage receives as feed the brine produced on the first stage). Each simulated RO train produces $6000 \mathrm{~m}^{3} /$ day of fresh water, with a total of 36000 $\mathrm{m}^{3} /$ day at nominal capacity (matching the output of the full-scale MED plant described in [2]).

The study focuses on the water production of the CSP-RO system using four different cooling systems with the CSP plant: Wet cooling (using fresh water), wet cooling (using seawater), dry cooling and once-through seawater cooling assuming no grid connection in all cases. The location chosen for the system is the city of Trapani, in the southern island of Sicily, in Italy. The simulation for the CSP plant was done by System Advisor Model's (SAM) (version 2014.1.14) physical trough model [9], using the integrated TRNSYS software program. SAM is a validated simulation program that can simulate the performance of CSP systems among other renewable energy systems using hourly resource data. The simulations for the once through and seawater wet cooling systems are performed using an add-on recently developed for SAM [2]. This add-on is also able to simulate the operation of a CSP-MED system, and the detailed hourly data describing the operation of the CSP-MED system used in this work to compare with the outputs of the CSP-RO system was obtained from the work described in [2] using this same add-on. It was defined that the CSPRO system operates in a way that ensures that, in both full and partial operation of the CSP plant, each train is operated either at $100 \%$ capacity or it is shut down, depending on availability of power under different water temperatures across the simulation period (one year). Pumping costs of the seawater from the intake to the high pressure pump of the RO system are not accounted for in this work. The water temperatures are expected to range yearly within $10-22^{\circ} \mathrm{C}$. A constant permeate flow is maintained by adjusting the feed pressure according to temperature in a way that keeps the same ratio of permeate flow against feed flow during operation. In the simulation, as an approximation it is assumed that the duration of both the start-up and shutdown of the RO unit is zero, e.g. the RO system will start-up or shutdown immediately, depending on availability of electric energy from the CSP plant (in reality full scale RO plants can perform the start-up and shutdown procuderes in a short amount of time, 5-15 minutes). These procedures vary a lot from plant to plant. Figure 4 shows a simpified scheme of the CSP-RO system considered in this work. 


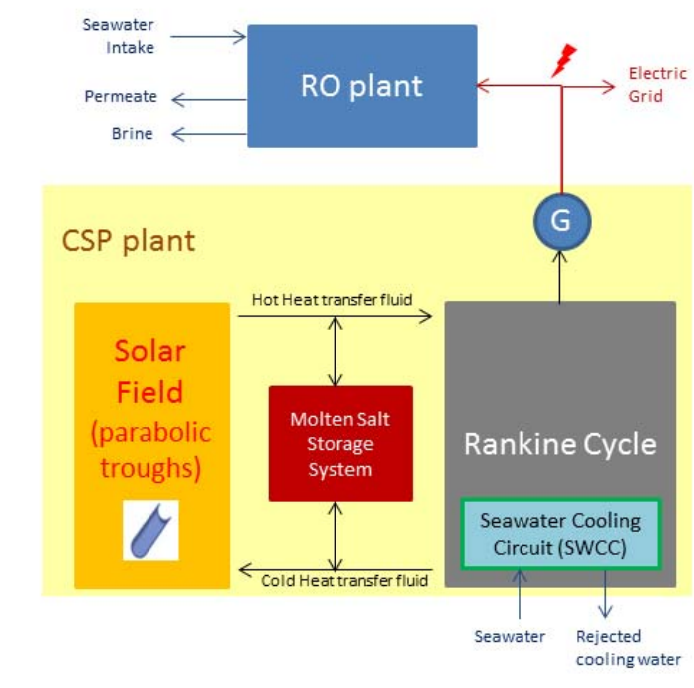

Figure 4 - Generic schematic Diagram of CSP-RO system

\subsection{Simulation Parameters}

The design and simulation of the RO plant is aimed to meet a water production of $36000 \mathrm{~m}^{3} /$ day matching the amount of water produced by a real MED plant in Trapani [8]. The CSP simulations used the predefined configuration found in SAM's physical trough model. The main changes were applied to the installed power, thermal storage hourly availability, solar multiple, and the weather data used to match the power capacity of the CSP-MED system in [2]. The weather file that was used was built by combining two sources: Meteonorm 5.1 database available in TRNSYS 16, and satellite data from the year of 1997 (from the latter namely, the Global Horizontal Irradiance (GHI), the Diffuse Horizontal Irradiance (DHI), both of these used to calculate then the DNI in TRNSYS). The original file from Meteonorm did not match the weather profile expected for the region, as it provided lower DNI values than expected from several other sources $\left(\sim 1310 \mathrm{kWh} / \mathrm{m}^{2} /\right.$ year versus $>1800 \mathrm{kWh} / \mathrm{m}^{2} /$ year $)$ [10][11]. The primary simulation inputs are displayed in table 3 .

The RO simulations are carried out using the ROSA model discussed in points 2. and 3. Several simulations were carried out to determine the optimum configuration for the RO plant, having into consideration the system design recommendations [5],[12]. The selected RO system considered a total of 3060 membranes (considering all the RO trains and stages), each of them designed for high salt rejection and low energy consumption with an area of $40.9 \mathrm{~m}^{2}$ each. ROSA was used to simulate one train only, and all 6 trains are considered identical in this system, thus, the whole RO system's performance can be estimated by multiplying the outputs from ROSA by the number of operating trains. The operational strategy is shown in figure 5. The algorithm used considered that whenever the CSP plant produces electricity, the present water temperature is read (water temperature affects the viscosity and subsequently the quality and flow rate of water through the membrane, therefore affecting RO system power consumption). Afterwards the algorithm checks whether the available power from the CSP system is sufficient to run 6 trains and registers the corresponding water production. Otherwise, it runs the same test for 5 trains and so on in a decending manner until it reaches 1 trains. If the power available is not enough to operate one train, the CSP-RO system doesn't produce any water and produces electricity only, and when the system produces water, the remaining power from the CSP is set as net electrical output. All the remaing net electricity produced by the CSP that is not used by the RO system is considered to be available to be injected into the electrical grid or used by some other process that may be attached connected directly to the CSP plant. This controlling algorithm described in figure 5, was implemented in Microsoft Excel environment.

The CSP-RO system is configured so that at least between May and August the capacity factors are between 65-85\%, and $75-80 \%$ for the CSP and RO plants respectively, aiming to reach the maximum number of hours of continuous operation by exploiting the increased availability of solar energy during that period.

\subsection{Results and discussion}

Using the chosen designs and configurations for the simulations, the resulting yearly capacity factors are between 41$45 \%$ for the CSP and an average of $48 \%$ for the RO system depending on the utilized cooling method. The financial factors were not used to optimize the size of CSP-RO system as economic costs are not accounted for in this study. 
Thus, it was not possible to determine the LCOE (Levelized Cost Of Energy) and the equivalent for water that would otherwise be used as a metric to size the CSP plant. The simulation results showed that the differences between yearly water productions under the four cooling system are minimal, in which all produce around $6,400,000 \mathrm{~m}^{3} / \mathrm{year}$ The two wet cooling (seawater and freshwater) options returning the highest net electricity production of $367,000 \mathrm{MWh}_{\mathrm{e}} / \mathrm{year}$ and being almost inseparable in performance. Although, using saltwater might be costly in the long run as it can cause faster degradation of plant components [13]. Using once-through seawater cooling provides slightly less power ( 2\%) around the year due to the relatively high condensation temperature forced through the system, and the distances and depth assumed for the seawater intakes. A lower condensation temperature, and intakes closer to the plant eventually would ensure better performance. Dry cooling is the worst in terms of power output, as it relies on the dry bulb temperature, which implies higher temperature in the down condenser of the Rankine cycle. It produces around 7\% less than the wet cooling options. The summary with the total yearly production of fresh water and electricity (net) using the different technologies assumed in the simulations, are presented in table 4.

Although the CSP plant produces significantly more electricity during the summer, the RO system capacity

Figure 5 - Operational Strategy of CSP-RO System

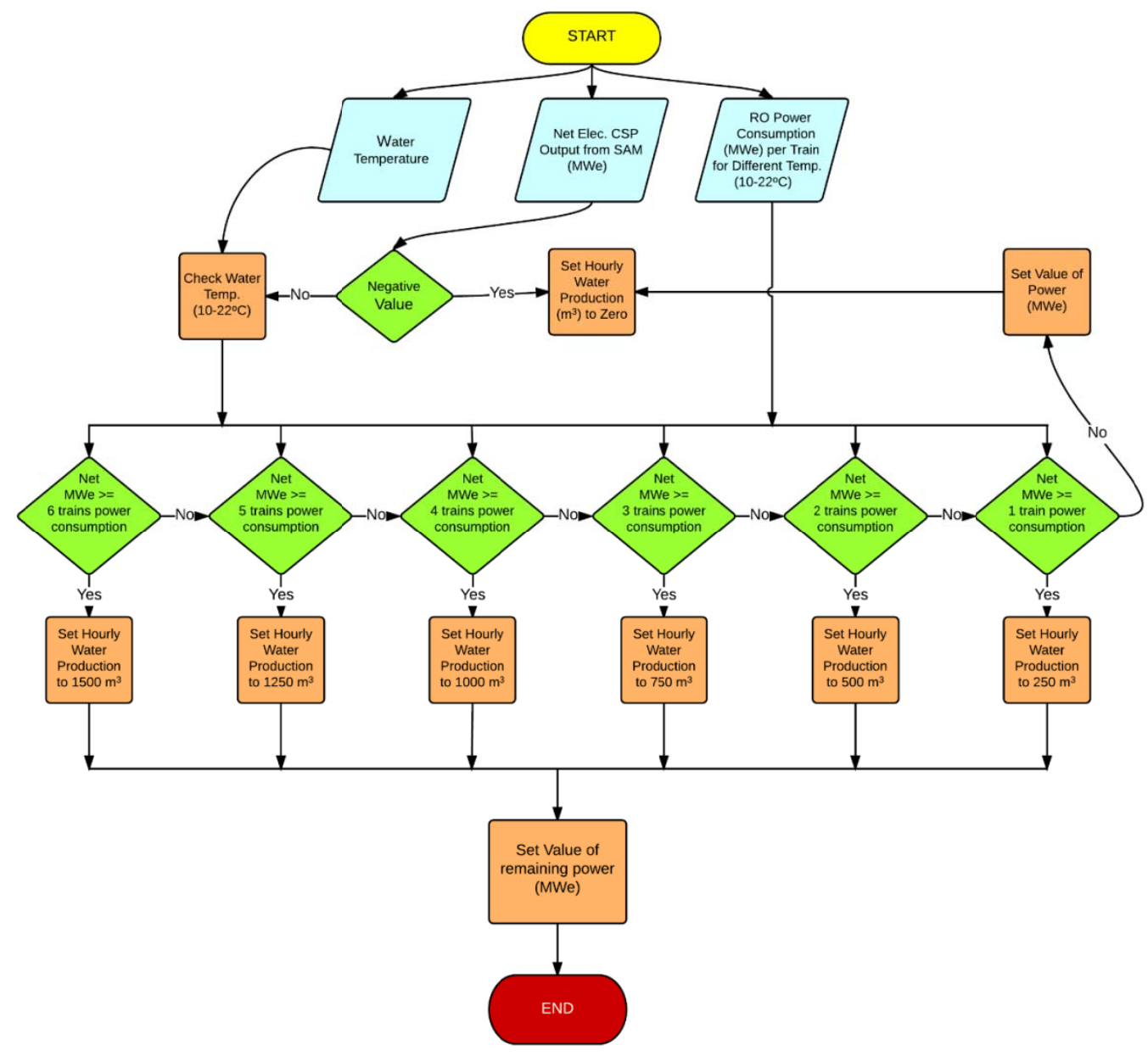


Table 3: Main Simulations Inputs for SAM and ROSA

\begin{tabular}{|c|c|c|}
\hline Input Value & Value & Units \\
\hline \multicolumn{3}{|l|}{ CSP Plant } \\
\hline Installed CSP Power (PT using oil as HTF) & 99 net (110 gross) & $\mathrm{MW}_{\mathrm{e}}$ \\
\hline Thermal Storage & 13 & $\mathrm{~h}$ \\
\hline Rated cycle conversion efficiency & 37.74 & $\%$ \\
\hline Condenser temperature for rated cycle conversion efficiency & 35 & ${ }^{\circ} \mathrm{C}$ \\
\hline Solar Multiple* & 3 & - \\
\hline Irradiation at design (reaching the solar field) & 950 & $\mathrm{~W} / \mathrm{m}^{2}$ \\
\hline Total collector loop conversion efficiency (Solargenix SGX-1) & 71.69 & $\%$ \\
\hline Design inlet temperature & 391 & ${ }^{\circ} \mathrm{C}$ \\
\hline Design outlet temperature & 291 & ${ }^{\circ} \mathrm{C}$ \\
\hline Operating boiler pressure & 100 & bar \\
\hline Hot standby period & 2 & $\mathrm{~h}$ \\
\hline Thermal power fraction for standby & 20 & $\%$ \\
\hline Max. turbine overdesign operation & 105 & $\%$ \\
\hline Min. turbine operation & 25 & $\%$ \\
\hline Direct normal irradiation (DNI) & 2004 & $\mathrm{kWh} / \mathrm{m}^{2} / \mathrm{yr}$ \\
\hline Fossil fill fraction $\dagger$ & 0 & $\%$ \\
\hline \multicolumn{3}{|l|}{$R O$} \\
\hline Total number of pressure vessels & $\mathrm{n}=85$ & - \\
\hline Pressure vessels staging Ratio & $49: 36$ & - \\
\hline Total number of membranes & $\mathrm{n}=3060$ & - \\
\hline Feed water flow rate & 13333 & $\mathrm{~m}^{3} /$ day \\
\hline System recovery rate & 45 & $\%$ \\
\hline Flow factor & 1 & - \\
\hline Water Temperatures & $10(\min ) / 22(\max )$ & ${ }^{\circ} \mathrm{C}$ \\
\hline Feed water salinity (TDS) & 40000 & $\mathrm{mg} / 1$ \\
\hline $\mathrm{pH}$ & 7.6 & - \\
\hline Pre-stage $\Delta \mathrm{P}$ & 0.345 & Bar \\
\hline Membrane Type & SW30HRLE-400i & - \\
\hline Pump Efficiency & 90 & $\%$ \\
\hline Energy Recovery Device Efficiency & 90 & $\%$ \\
\hline \multicolumn{3}{|l|}{ Once through seawater cooling } \\
\hline Distance between plant and water intake tube & 2000 & $\mathrm{~m}$ \\
\hline Intake tube water velocity & 0.3 & $\mathrm{~m} / \mathrm{s}$ \\
\hline Temperature approach & 5 & ${ }^{\circ} \mathrm{C}$ \\
\hline Distance between plant and end of brine discharge tube & 2000 & $\mathrm{~m}$ \\
\hline Brine tube water velocity & 0.3 & $\mathrm{~m} / \mathrm{s}$ \\
\hline Plant site elevation above sea level & 10 & $\mathrm{~m}$ \\
\hline Water storage tank distance from plant & 100 & $\mathrm{~m}$ \\
\hline Water storage tank height & 5 & $\mathrm{~m}$ \\
\hline Condensation temperature & 40 & ${ }^{\circ} \mathrm{C}$ \\
\hline \multicolumn{3}{|l|}{ Dry cooling } \\
\hline Minimum condenser pressure & 2 & inHg \\
\hline Initial temperature difference at design & 16 & ${ }^{\circ} \mathrm{C}$ \\
\hline \multicolumn{3}{|l|}{ Wet cooling } \\
\hline Minimum condenser pressure & 1.25 & inHg \\
\hline Approach temperature & 5 & ${ }^{\circ} \mathrm{C}$ \\
\hline
\end{tabular}

*The solar multiple makes it possible to represent the solar field aperture area as a multiple of the power block rated capacity. A solar multiple of one $(\mathrm{SM}=1)$ represents the solar field aperture area that, when exposed to solar radiation equal to the design radiation value (irradiation at design), generates the quantity of thermal energy required to drive the power block at its rated capacity (design gross output), accounting for thermal and optical losses. [9]

$\dagger$ fraction of the power block design turbine gross output from the Power Block that can be met by the backup boiler. 
Table 4 - Total outputs summary for $\mathrm{m}^{3}$ of fresh water produced and net electrical production with the different configurations assumed.

\begin{tabular}{|c|c|c|c|}
\hline \multicolumn{2}{|c|}{ CSP+RO (Wet cooling) } & \multicolumn{2}{c|}{ CSP+RO (Dry cooling) } \\
\hline $\mathrm{m}^{3} / \mathrm{yr}$ & $\mathrm{MWh}_{\mathrm{e}} / \mathrm{yr}$ & $\mathrm{m}^{3} / \mathrm{yr}$ & $\mathrm{MWh}_{\mathrm{e}} / \mathrm{yr}$ \\
\hline 6408000 & 367273 & 6414500 & 341550 \\
\hline
\end{tabular}

\begin{tabular}{|c|c|c|c|}
\hline \multicolumn{2}{|c|}{ CSP-RO/SWCC } & \multicolumn{2}{c|}{ CSP+MED/SWCC } \\
\hline $\mathrm{m}^{3} / \mathrm{yr}$ & $\mathrm{MWh}_{\mathrm{e}} / \mathrm{yr}$ & $\mathrm{m}^{3} / \mathrm{yr}$ & $\mathrm{MWh}_{\mathrm{e}} / \mathrm{yr}$ \\
\hline 6410500 & 360569 & 5454052 & 297017 \\
\hline
\end{tabular}

remains the same and cannot consume the available extra energy, resulting in an increase of the net electrical production available for other uses during those months. Assessing the quality of water produced (permeate) throughout the year in figure 6 it is seen that the levels of TDS increase as water temperatures increase and vice versa. The variation in temperature affects the salt diffusion across the membranes and flow rates, and since the salinity of the feed water is fixed and the amount of pressure applied depends on the quality of the water treated, the feed pump continues to apply pressure without considerable changes throughout the year, countering most of the changes in flow due to increase of temperature. Therefore, both feed pressure and flow rates through the system are considered constant throughout the year. Thus, the produced water quality is only affected by the changes in temperature. Today an increasing number of reverse osmosis systems use electrical motors with variable speed drives that can adjust both flow and feed pressure of the pump over a broad range, with little losses in efficiencies to enable further control of permeate quality. The average water quality for the simulation period of one year using the CSP-RO studied system, is $\sim 156 \mathrm{mg} / \mathrm{l}$ TDS, satisfying WHO (World Health Organization) standards, that allow a maximum salinity of $250 \mathrm{mg} / \mathrm{l}$ for drinking water. The results of the CSP-RO simulations show that the choice of cooling system does not affect the water production by much, only the amount of electricity generated. Additionally, all performance parameters are within close margins of each other. The selection of the configuration using a cooling system depends mostly on site location and availability of water for cooling.

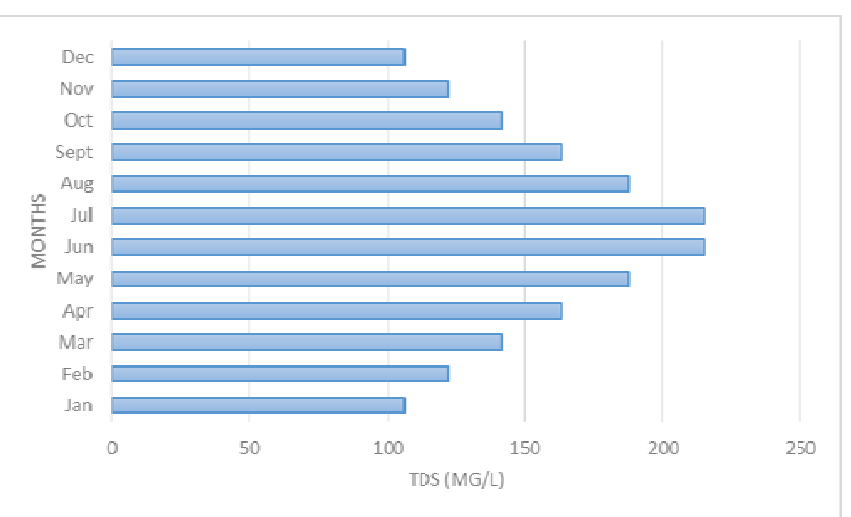

Figure 6 - Water quality across the year

\subsection{Comparison of Technical Perfomances}

In this section, the performance of the CSP-RO system described above is compared to a CSP-MED system. This CSP+MED system, consists of a $110 \mathrm{MW}_{\mathrm{e}}$ (gross) parabolic trough CSP plant coupled with a lowtemperature MED parallel-feed plant analyzed in [2], using the add-on previously mentioned in 4.1. Both $\mathrm{CSP}+\mathrm{RO}$ and CSP+MED systems are assumed to be connected to once-through cooling system, also described in [2] as Sea Water Cooling Circuit (SWCC). It is assumed that the most likely configuration for the $\mathrm{CSP}+\mathrm{RO}$ will be installed near the sea, and therefore using seawater with a once through condenser with the Rankine cycle. This configuration also allows a more straightforward comparison of results with the CSP+MED/SWCC configuration. On the CSP-MED simulation, the SWCC is designed to absorb the total amount of rejected heat by the CSP plant at design conditions. Both the RO and MED systems being compared have a nominal production capacity of 36000 $\mathrm{m}^{3}$ /day (the same as the real TVC-MED plant at Trapani). Analyzing the performance of the two, in figure 7, it is clear to see that the production profile is in line with the typical Mediterranean climate, peaking during summer and sharply declining during winter time, despite the use of a large thermal storage capacity, and a solar multiple of three for both CSP-MED and CSP-RO system. The rate of parasitic consumption also falls in line with this profile. The CSP parasitic consumptions accounted and described in [9] include auxiliary boiler parasitic load, fixed parasitic load, balance of plant parasitic load, total parasitic power for tank freeze protection, solar collector assemblies drives and electronics parasitic power, thermal energy storage and power block heat transfer fluid pumping power, collector field required pumping power, power block cooling parasitic power, and collector field required freeze protection parasitics and the pumping power for RO and MED in each system. Overall the CSP$\mathrm{RO} / \mathrm{SWCC}$ system has more parasitic consumption than CSP-MED/SWCC as seen in figure 9. This is because the MED system does not use a high pressure pump. Therefore, the pumping power required for the RO is significantly higher than for the MED. Despite that, the CSP-RO system produces more electricity throughout the year as coupling MED to a CSP plant introduces a considerable cutback on the potential electric production 
of the power block of the plant [2] due to the high thermal extraction of the MED.

The production of electricity and water is much lower during the winter months than in the summer time for both CSP-RO and CSP-MED systems, as the solar resource is scarce during this period for the studied location. Compared to the CSP-MED system, the CSPRO system produces significantly more fresh water during the winter months, particularly in November and December in which the CSP-RO produces more than double of that of the CSP-MED. That is because there are several days during this period where the CSP-MED plant will not operate at all, or at capacities below the minimum for the MED to operate, while CSP-RO would still operate due to higher performance affiliated with the cooling system in comparison to the CSP-MED, and also the fact that for the MED system in [2] it was also assumed to be only one single train, while for the CSPRO simulation the RO was subdivided into 6 trains. The CSP-RO system increases its performance compared to the CSP-MED system through the warmer months of the year, regarding the net electricity (Fig. 7), and in the colder months regarding the water production (Fig.8).

Overall, the CSP-RO system provides around $20 \%$ more electricity and water throughout the year. The calculated specific energy consumption for pumping only is 2.81 $\mathrm{kWh} / \mathrm{m}^{3}$ [2] and $3.32 \mathrm{kWh} / \mathrm{m} 3$ for the CSP-MED and CSP-RO system respectively (although it is important to mention that, unlike for the CSP-MED system, no pumping costs are assumed for the RO between the seawater inlet and the high pressure pump). Using data from [2], the MED coupling to the CSP plant introduces a cutback on the potential electric production equivalent to $15.54 \mathrm{kWh} / \mathrm{m}^{3}$ for the Trapani case study. Such high figure results from the oversizing of the CSP plant compared to the MED. With that design, when the CSP exhaust steam heat load goes above the maximum heat absorption capacity of the MED plant (which in the simulation from [2] was set to $40 \%$ of the nominal heat load output from the CSP), the remaining exhaust steam is routed into the SWCC. The SWCC is set to operate at the same vapor pressure than the steam entering the MED plant. In these conditions, only part of the exhaust steam is being used to power the MED and produce fresh water. This produces an excessive cutback on electric production due to the forced condensation at high pressure of the entire mass steam flow, and not only of the steam flowing into the MED. On the other hand this strategy ensures that the MED plant will operate more times during the year at nominal capacity.

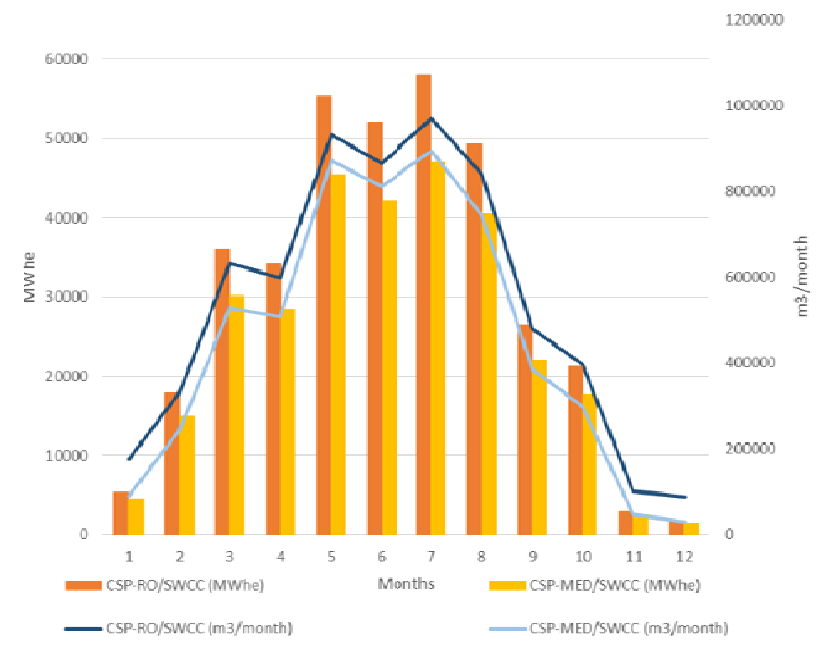

Figure 7 - Comparison of net electrical and water production

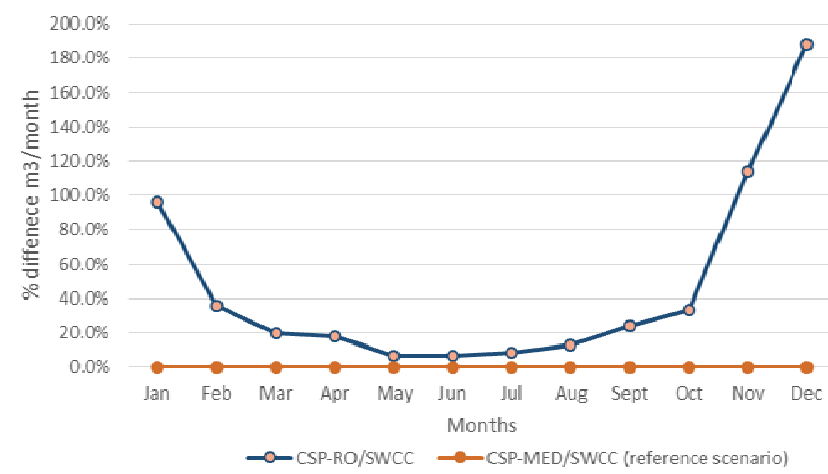

Figure 8 - Percentage of difference of water production

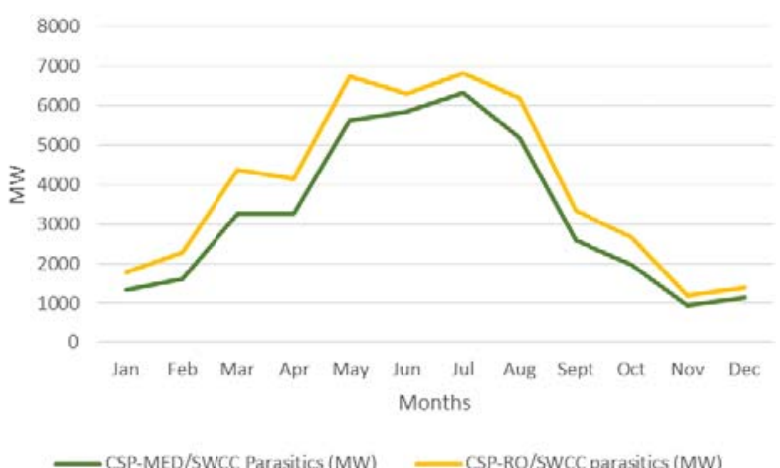

Figure 9 - Comparison of parasitic consumption

The performances of the two systems for a typical day in winter (January $3^{\text {rd }}$ ) and summer (July $1^{\text {st }}$ ) can be seen in Fig.10 and Fig.11. In the winter day, the lack of solar irradiation prevents nominal operation, and both plants are only able to operate for a few hours. The CSP-RO plant can only start to produce water at around $12 \mathrm{pm}$, and produces water at nominal capacity for a period of 6 hours, during which the CSP-MED system starts producing water not only an hour later, but also nominal production occurs for a shorter period. The CSP-RO system produces in total, more water than the CSP-MED combination. In the summer day, both systems operate at nominal capacity production of $1500 \mathrm{~m}^{3} / \mathrm{h}$ throughout the 
day, while the CSP-RO system produces slightly more electricity than the CSP-MED. Other CSP+MED configurations can achieve better results than the one studied in [2], thus the previous discussion is valid only for the configurations discussed in this work and not generally valid for all kinds of CSP-MED integration schemes.

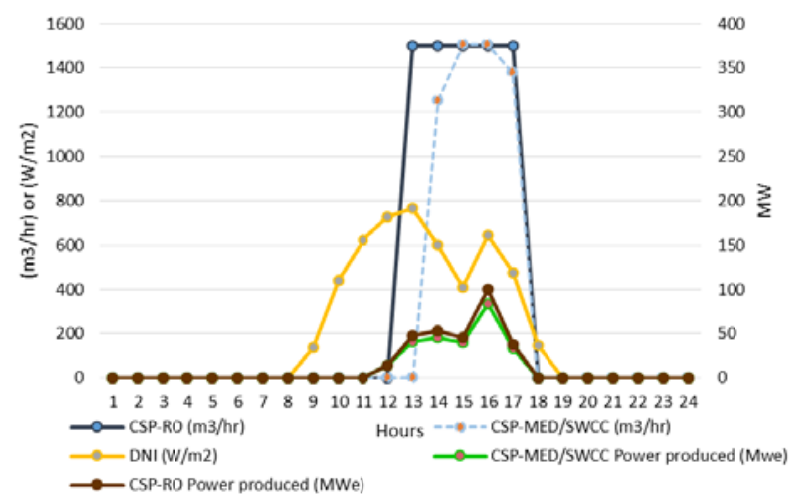

Figure 10 - Typical Performance in Winter Day

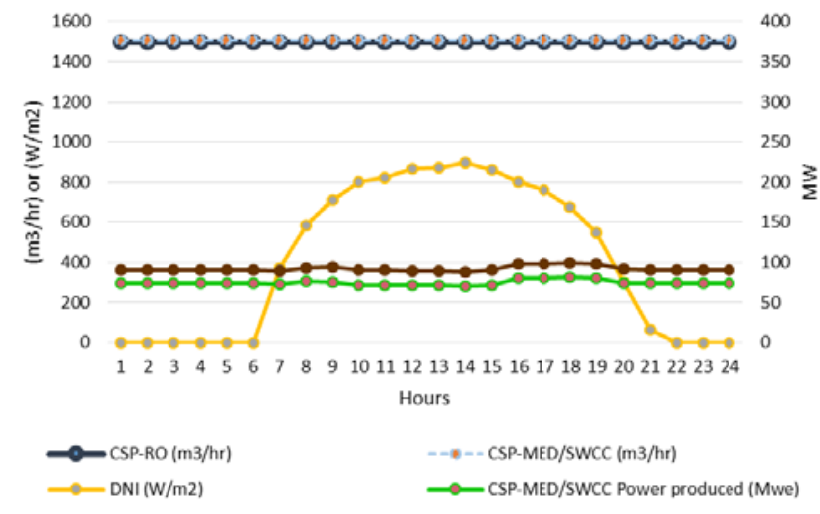

$\longrightarrow$ CSP-ROPOWer produced (MWe)

Figure 11 - Typical Performance in Summer Day

\section{CONCLUSIONS}

This report presents the results for the yearly physical performance of a potential CSP-RO system operating in a cogeneration scheme with no grid connection, for a location where a commercial large scale stand-alone MED plant has operated until very recently near the city of Trapani, west Sicily, Italy. The results of the operation of this CSP-RO system are compared with data from the real MED plant [8] and with data of a CSP-MED system obtained from a previous work [2]. This integrated comparison between RO and MED technologies powered by CSP is a novelty as far it was possible for the authors to verify in the literature regarding the level of detailed results presented for a case-study in specific location where it is also possible to compare with data from a real commercial plant. The quality of the results obtained, are in line with the requirements for preliminary feasibility analysis on such type of investments.

This work was conducted using a commercial reverse osmosis computer model (ROSA) developed by DOW
FILMTEC $^{\mathrm{TM}}$ and a software developed by NREL capable of simulating the hourly operation of a CSP plant, with the aid of a recently developed add-on developed in a previous work [2].

During the execution of this work it was also possible to validate the ROSA model with data from an existing RO plant in Alvor, located in the Southern region of Portugal, Algarve. The data, for nominal conditions, was provided during a technical field visit to this plant. ROSA assumes steady-state operation and can only simulate single point operation, which is then adapted to hourly values in the CSP-RO simulation in Microsoft Excel environment. The primary inputs of the model comprised of the number of membranes, seawater quality and temperature, and membrane's type. The results show that the main performance outputs such as, flow rates and salinities of the permeate and concentrate and the feed pump pressure fell within a $10 \%$ margin of error compared to the fullscale data used.

The case study in this report is chosen to compare the performance of a CSP-RO system to an existing thermal desalination plant [8], and to a CSP-MED system studied in previous work [2]. Simulation were performed for the operation of the CSP+RO system using four different cooling systems (Dry Cooling, Wet Cooling (seawater and freshwater) and SWCC). Results shows that there are minimal differences in water production for the CSP-RO system using any of the four cooling options. Regarding the electrical production of the $\mathrm{CSP}+\mathrm{RO}$, there is a small difference $(\sim 2 \%)$ between the wet cooling options versus once-through seawater cooling (SWCC) outputs. When using dry cooling the cutback on electrical production is more significant $(\sim 7 \%)$, as expected when compared to the wet cooling options. The decision to use a particular cooling system comes down to site location and water availability when it comes to designing such a system.

The CSP-RO/SWCC gross installed capacity is 110 $\mathrm{MW}_{\mathrm{e}}$, and has a nominal water production of 36000 $\mathrm{m}^{3} /$ day chosen to match those of the CSP-MED/SWCC system analyzed in [2]. The CSP+MED system has a net electric production of $297 \mathrm{GWh}_{\mathrm{e}}$ and 5.4 million $\mathrm{m}^{3}$, and the $\mathrm{CSP}+\mathrm{RO}$ has $360 \mathrm{GWh}_{\mathrm{e}}$ and 6.4 million $\mathrm{m}^{3}$. The CSP-MED configuration had capacity factors of $34.2 \%$ and $41.4 \%$ for the CSP and MED plants, respectively, while the CSP-RO had capacity factors of $44 \%$ and $48 \%$ for the CSP and RO plant, respectively.

Although the electric consumption for the pumping in the $\mathrm{RO}$ is significantly higher than for MED, the year-round performance of the CSP-MED for the case study of Trapani is worse due to the lower performance of the Rankine cycle when using the MED as part of the cooling system instead of using only a SWCC instead. Accordingly the CSP-RO provides significantly more electricity during the summer, while more than doubling the water production of the CSP-MED during some 
months in winter. The MED consumption for pumping only $\left(2.81 \mathrm{kWh} / \mathrm{m}^{3}\right)$ is slightly lower than that of the RO $\left(3.32 \mathrm{kWh} / \mathrm{m}^{3}\right)$ which highly depends on the salinity of the input water (it is important to note that no pumping energy costs are assumed between the intake and the RO plant in the simulations conducted in this work). For the Trapani case study the cutback introduced by the MED coupling to the CSP plant is equivalent to $15.54 \mathrm{kWh} / \mathrm{m}^{3}$. The plant settings leading to this high value, favored the number of hours that the MED would operate at nominal capacity instead of optimizing the average cutback that the MED plant would impose on the electric production of the CSP plant. Other CSP+MED configurations can achieve better results than the one studied in [2] implying that the present conclusions are not generally valid for all CSP+MED integration schemes but only for the configurations described in the present work.

From the analysis above, it is seen that the electricity yield of the CSP-MED is considerably lower. This is due to the high cold end temperature of the steam turbine which result in the delivery of less mechanical work to the power generator than in the case of using a steam turbine with lower cold end temperature as in the case of RO representing the difference (cutback) in electricity production. The MED reduces significantly the potential electrical production of the CSP plant for the case study of Trapani. In order to produce the water amount equal to the full scale plant found at Trapani, using the same capacity factor for the RO unit of $48 \%$ achieved in the simulations, the number of trains in the RO system has to double e.g. system will have a nominal capacity of 72000 $\mathrm{m}^{3} /$ day.

Future work should include the economic evaluation of the two configurations in order to determine the best option for any specific site. Additionally, the effects of the partial operation of the RO system should be investigated over the long term to determine the economic viability of such an operating strategy as used in the CSP-RO coupling, and the option of grid integration. Finally, the comparison should be performed against different CSP+MED configurations.

Although, the results are in favor of the CSP-RO configuration for the case study of Trapani, the coupling of CSP and MED has many advantages. For example, the MED system replaces the cooling system of the CSP plant, and all the power consumption is related to water pumping. On the other hand, CSP and RO systems can be completely separated, allowing the installation of CSP in potentially more suitable locations inland. The losses due to transportation of electricity must be accounted for in this CSP-RO configuration.

As the results show, the electric production follows a typical seasonal pattern similar to that of most CSP systems, in which lower levels of production occur in winter, and the highest level in summer, due to the increased availability of solar irradiation. Interestingly, this falls in line with the water and electricity demand profile at Trapani, with high demands during the summer time and low demands in winter [2]. Additionally, largescale water storage is possible in the region, as rainwater can be and is usually collected in the winter time and stored in artificial lakes, acting as large open reservoirs. Thus, for the location of Trapani, water production using desalination plants does not require a constant output throughout the year. Also, there's the possibility of connecting the system to the grid, if necessary, to sustain the operation during nighttime and/or in winter. The peak demand could be met by the CSP-RO/SWCC system and in winter, the lakes and reservoirs could provide freshwater. A hybrid CSP-MED/RO plant could also be considered, where the exhaust steam from the Rankine cycle is fed into the MED system, while most of the net electric power is delivered to the RO unit. This kind of integration could also aid in providing higher purity product water with the RO system using less stages, by blending the output water of the two systems. Thus, improving the overall water quality and avoiding the installation of a multistage RO system which in turn, reduces energy consumption. The combination of $\mathrm{RO}$ and MED also allows for greater flexibility in the production of water and electricity by adapting to seasonal demand. Therefore, the system could benefit from the RO technology's improved production during winter compared to MED when coupled with CSP for the case study of Trapani. Combining MED and RO allows to use a common water intake unit with the consequent decreases is cost of civil works and reduction in pumping energy [14]. On the other hand, interconnecting these three systems (CSP+MED+RO) could also lead to operational issues more frequently.

Finally, CSP desalination is a promising field in the development of medium and large-scale renewable energy desalination and could compete in the medium term with conventional desalination techniques. It can be the future solution to the MENA region's water issues. Thus, there is a need for further research and development of CSP technologies, and further testing of its coupling with different desalination technologies under multiple conditions to further analyze the cogeneration potential of fresh water and electricity using these technologies.

\section{ACKNOWEDGEMENTS}

The authors would also like to thank both Eng. David Loureiro and Cátia Jorge from LNEG for their help organizing and collecting data from the technical visit to the Alvor RO plant. Additionally, the author would like to extend the gratitude to the members of the Pestana Hotel Management. Eng. Joaquim Santos, Eng. Pedro Rosendo França and Mr. Paulo Justino for providing the opportunity to visit and collect data from the Alvor plant. The authors would also like to acknowledge the EU and the seventh framework program for the financial support 
of this work under the STAGE-STE project with contract number 609837.

\section{Nomenclature}

\begin{tabular}{|c|c|}
\hline $\mathbf{S}$ & membrane area $\left(\mathrm{m}^{2}\right)$ \\
\hline $\begin{array}{l}\text { A } \\
\mathrm{m}^{2} \cdot \text { h.bar) }\end{array}$ & water permeability \\
\hline B & salt permeability constant (m/day) \\
\hline $\mathbf{C b}$ & bulk concentration $(\mathrm{mg} / \mathrm{L})$ \\
\hline $\mathbf{C f}$ & feed concentration $(\mathrm{mg} / \mathrm{L})$ \\
\hline Cfc & concentrate feed concentration $(\mathrm{mg} / \mathrm{L})$ \\
\hline $\mathbf{C P}$ & concentration polarization factor (-) \\
\hline Cp & permeate concentration $(\mathrm{mg} / \mathrm{L})$ \\
\hline $\begin{array}{l}\text { Cw } \\
(\mathrm{mg} / \mathrm{L})\end{array}$ & membrane surface \\
\hline FF & fouling factor (-) \\
\hline $\mathbf{Q}$ & permeate water flux $\left(\mathrm{L} / \mathrm{m}^{2} . \mathrm{h}\right)$ \\
\hline n & number of RO elements in series (-) \\
\hline NA & Salt flux (-) \\
\hline $\begin{array}{l}\sum \mathbf{m} \mathbf{j} \\
\text { constituents in a }\end{array}$ & $\begin{array}{l}\text { sum of molality concentration of all } \\
\text { solution (moles of solute } / \mathrm{kg} \text { of solvent) }\end{array}$ \\
\hline Pcd & concentrate side pressure drop (bar) \\
\hline Pf & Feed pressure (bar) \\
\hline $\mathbf{P p}$ & Permeate pressure (bar) \\
\hline$\Delta \mathbf{P}$ & membrane pressure gradient (bar) \\
\hline Qc & concentrate flow rate $\left(\mathrm{m}^{3} / \mathrm{h}\right)$ \\
\hline Qf & feed flow rate $\left(\mathrm{m}^{3} / \mathrm{h}\right)$ \\
\hline Qp & permeate flow rate $\left(\mathrm{m}^{3} / \mathrm{h}\right)$ \\
\hline $\begin{array}{l}\mathbf{Q}_{\mathrm{fc}} \\
\left(\mathrm{m}^{3} / \mathrm{h}\right)\end{array}$ & average concentrate side flow rate \\
\hline $\mathbf{R}$ & recovery rate (-) \\
\hline $\mathbf{R j}$ & membrane rejection rate $(-)$ \\
\hline $\mathbf{T}$ & feed temperature $\left({ }^{\circ} \mathrm{C}\right)$ \\
\hline TCF & temperature correction factor $(-)$ \\
\hline$\Delta \pi$ & osmotic pressure gradient (bar) \\
\hline $\begin{array}{l}\text { זave } \\
\text { pressure (bar) }\end{array}$ & average concentrate side osmotic \\
\hline $\boldsymbol{\pi f}$ & feed osmotic pressure (bar) \\
\hline$\pi p$ & permeate osmotic pressure (bar) \\
\hline
\end{tabular}

\section{REFERENCES}

[1] MENA Development Report - "An Emerging Solution to Close the Water Gap in the Middle East and North Africa", The World Bank, 2012.

[2] Sérgio Casimiro, João Cardoso, Christos Ioakimidis, J. Farinha Mendes, Carmelo Mineo \& Andrea Cipollina (2014): MED parallel system powered by concentrating solar power (CSP). Model and case study: Trapani, Sicily, Desalination and Water Treatment, DOI: 10.1080/19443994.2014.940222.

[3] C. Temstet, G. Canton, J. Laborid, A. Durante, A large high-performance MED plant in Sicily, Desalination 105 (1996) 109-114.

[4] Ali Altaee, Computational model for estimating reverse osmosis system design and performance: Part-one binary feed solution, Desalination 291 (2012) 101-105.

[5] Dow Water \& Process Solutions; FILMTECTM Reverse Osmosis Membranes Technical Manual
[6] Erika Mancha, Don DeMichele, W. Shane Walker, Thomas F. Seacord, Justin Sutherland, Aaron Cano, "Part II. Performance Evaluation of Reverse Osmosis Membrane Computer Models", Texas Water Development Board, 2014.

[7] Dow Chemical Company, 2014, Reverse Osmosis Cross Reference Tool. Accessed: 23 September 2014,

< http://www.dowwaterandprocess.com/en/resources/rocross-reference-tool $>$

[8] A. Cipollina, G. Micale, L. Rizzuti, A critical assessment of desalination operations in Sicily, Desalination 182 (2005) 1-12.

[9] M. Wagner, P. Gilman, Technical Manual for the SAM Physical Trough Model, Technical report NREL/TP- 55000-51825, National Renewable Energy Laboratory, Golden, CO, 2011.

[10] GeoModelSolar, 2011, SolarGIS-Solar-map-DNIItaly-en.png. Assessed 30 September 2014 $<$ http://solargis.info/doc/_pics/freemaps/1000px/dni/Solar GIS-Solar-map-DNI-Italy-en.png>.

[11]ABB, Technical Application Papers No. 10: Photovoltaic plants. Assessed 30 September 2014, $<$ http://www04.abb.com/global/seitp/seitp202.nsf/c71c66 c1f02e6575c125711f004660e6/d54672ac6e97a439c1257 7ce003d8d84/\$file/vol.10.pdf>.

[12] A.M. Delgado-Torres, L Garcia-Rodriguez, V.J. Romero-Ternero, Preliminary Design of a solar thermalpowered reverse osmosis system, Desalination 216 (2007) 292-205.

[13] J. Maulbetsch, M. DiFilippo, Performance, Cost, and Environmental Effects of Saltwater Cooling Towers, California Energy Commission, PIER Energy-related Environmental Research Program, Berkeley, CA, 2008.

[14] G. Iaquaniello, A. Salladini, ,A.Mari, A.A.Mabrouk, H.E.S. Fath, 2014, "Concentrating solar power (CSP) system integrated with MED-RO hybrid desalination", Desalination, Volume 336, Pages 121-128, Elsevier. 